\title{
Radiation Effects on Materials Used in Geological Repositories for Spent Nuclear Fuel
}

\author{
Mats Jonsson \\ Division of Applied Physical Chemistry, School of Chemical Science and Engineering, KTH Royal Institute of Technology, \\ 10044 Stockholm, Sweden \\ Correspondence should be addressed to Mats Jonsson, matsj@kth.se
}

Received 4 November 2012; Accepted 23 November 2012

Academic Editors: R. A. Dunlap, Y. Masuda, J. Rubio, and R. A. Varin

Copyright (C) 2012 Mats Jonsson. This is an open access article distributed under the Creative Commons Attribution License, which permits unrestricted use, distribution, and reproduction in any medium, provided the original work is properly cited.

Safe long-term storage of radioactive waste from nuclear power plants is one of the main concerns for the nuclear industry as well as for governments in countries relying on electricity produced by nuclear power. A repository for spent nuclear fuel must be safe for extremely long time periods (at least 100000 years). In order to ascertain the long-term safety of a repository, extensive safety analysis must be performed. One of the critical issues in a safety analysis is the long-term integrity of the barrier materials used in the repository. Ionizing radiation from the spent nuclear constitutes one of the many parameters that need to be accounted for. In this paper, the effects of ionizing radiation on the integrity of different materials used in a granitic deep geological repository for spent nuclear fuel designed according to the Swedish KBS-3 model are discussed. The discussion is primarily focused on radiationinduced processes at the interface between groundwater and solid materials. The materials that are discussed are the spent nuclear fuel (based on $\mathrm{UO}_{2}$ ), the copper-covered iron canister, and bentonite clay. The latter two constitute the engineered barriers of the repository.

\section{Introduction}

The handling of radioactive waste in general and spent nuclear fuel in particular is one of the main concerns in connection to nuclear power. For the used nuclear fuel there, are essentially two options: reprocessing to produce new fuel from fissile material present in the used fuel or final disposal. Both options have their advantages and disadvantages, and the choice is to a large extent a political issue where nonproliferation is a key component. Reprocessing reduces the volumes of high-level radioactive waste, but it does not solve the waste issue completely. Repositories for radioactive waste must be employed, regardless of which nuclear fuel cycle is being used.

One of the most developed repository concepts is the KBS-3 model for long-term storage of spent nuclear fuel in granitic bedrock. The concept has been developed by the Swedish Nuclear Fuel and Waste Management Company (SKB) [1] and has also been adopted by Finland [2].
An application for building a repository according to the KBS-3 model is currently being processed in Sweden [3] where a once-through fuel cycle is used.

The KBS-3 model is described schematically in Figure 1.

After cooling for a period of at least 30 years, the fuel elements are placed in cast iron canisters with an outer layer of copper. The thickness of the copper layer is $5 \mathrm{~cm}$. The canisters are sealed and placed in vertical holes drilled in tunnels around 500 meters below ground. In the vertical holes, the canisters are embedded in compacted bentonite clay. When the repository is full, the tunnels will be back filled. This is a multibarrier system where the canister is the innermost barrier, bentonite clay is the second barrier and the granitic bedrock is the third barrier. The main purpose of the barriers is to protect the spent nuclear fuel from rock movement and groundwater and to prevent the release of radioactive materials to the biosphere. Another function of the barrier system is to prevent human intrusion. Barrier function must be maintained for at least 100000 


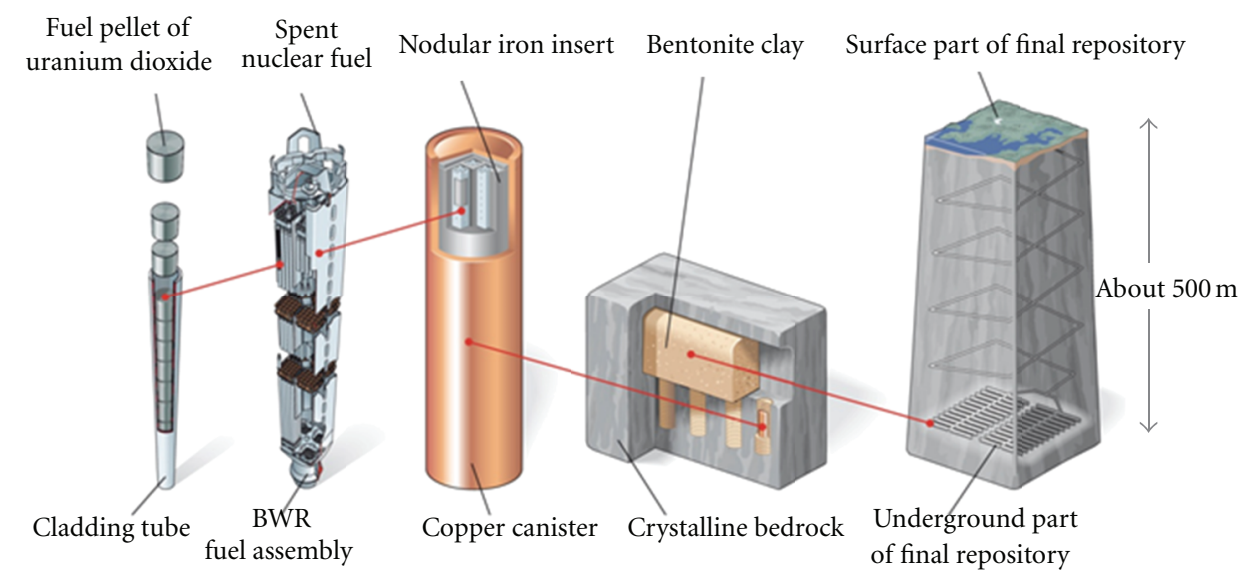

FIgure 1: Schematic view of the KBS-3 concept. Reproduced with permission from the Swedish Nuclear Fuel and Waste Management Company $(\mathrm{SKB})$.

years to guarantee that future generations are not affected. The integrity of these engineered and natural barriers has been studied since the early 1980s. The main purpose of these studies is to provide input data for the extensive safety analysis that must be performed before a decision to build a repository can be made. Given the time span stated previously, long-term predictions of barrier behavior are bound to be extreme extrapolations. For this reason, it is essential that the models used are based on a solid scientific ground and that the data used are of the highest possible accuracy.

The long-term evolution of material properties in a geological repository for spent nuclear fuel will depend on a number of different parameters such as seismic activity, groundwater chemistry, groundwater flow, and microbiological activity. In addition to what other materials in the same environment are exposed to, the materials in a spent nuclear fuel repository are also exposed to ionizing radiation originating from the radioactive components of the fuel. The spent nuclear fuel emits alpha, beta, gamma, and neutron radiations. The relative intensity of the different types of radiation depends on the fuel age and the distance from the fuel. Under normal operation when all barriers are intact, the canister (iron and copper) and the bentonite barrier will be exposed to gamma and neutron radiations. Alpha and beta radiations have a more limited range and can be absorbed by the fuel cladding. Upon barrier failure, groundwater will eventually come into contact with the spent nuclear fuel. Water adjacent to the fuel will then be exposed to all four types of radiation. This will induce radiolysis of water, producing oxidants and reductants capable of reacting with the fuel. Hence, radiation effects on the materials constituting the barrier system of the repository are of key importance in the safety analysis. Admittedly, radiation effects on materials are crucial for the performance on safety of other nuclear technological applications. The main differences are that for other applications, such as nuclear power plants, the radiation is more intense and the time spans of interest are considerably shorter than in the case of a deep repository for spent nuclear fuel. In this paper, a summary of this research field focusing on radiationinduced interfacial processes is provided. The interfacial processes that are covered here are radiation induced dissolution of the spent nuclear fuel matrix, radiation-induced corrosion of copper, and radiation effects on bentonite clay. After a short summary of radiation effects on materials in general, each material type is treated separately.

\section{Radiation Effects on Materials}

Radiation energy absorbed by a material can be quantified as the absorbed dose. The SI unit for absorbed dose is $1 \mathrm{~Gy}\left(1 \mathrm{~J} \mathrm{~kg}^{-1}\right)$ [4]. Ionizing radiation interacts with matter in several ways. At moderate energies (e.g., alpha, beta, and gamma radiations originating from radioactive decay), the radiation energy will be absorbed by the electrons of the absorber [4]. This will initially cause excitations and ionizations and eventually result in more permanent chemical changes. In addition to the changes in electron configuration of the absorber, neutron radiation may also cause activation of the material or dislocation of atoms [5]. Heavy particle radiation (such as alpha radiation) can also cause dislocations [5].

2.1. Radiation Effects on Pure Water. The radiation chemistry of water has been extensively studied for more than half a century [4]. The current state of the art is described in detail in numerous publications [6]. Absorption of radiation energy in liquid water initially leads to the formation of excited and ionized water. In both cases, the products are very unstable and rapidly undergo fragmentation to produce free radicals and ionic species. These events are highly localized, and the density of excitations and ionizations depends on the type and energy of radiation [4]. Due to the high mobility of species dissolved in liquid water, free radicals will react with each other to give molecular products. After about $0.1 \mu \mathrm{s}$, the solution has become more homogeneous, and the following products can be identified in pure irradiated water: $\mathrm{HO}^{\circ}, \mathrm{H}^{\circ}$, $\mathrm{HO}_{2}{ }^{\circ}, \mathrm{e}_{\mathrm{aq}}{ }^{-}, \mathrm{H}^{+}, \mathrm{H}_{2}$, and $\mathrm{H}_{2} \mathrm{O}_{2}$. The yields of these products 
are referred to as $G$-values (SI unit: $\mathrm{mol} \mathrm{J}^{-1}$ ). The $G$-values depend on the type and energy of the radiation [4].

Some of the radiolysis products stated previously are free radicals, and they display a significant chemical reactivity. To summarize, radiolysis of water creates conditions enabling fairly extreme redox chemistry.

2.2. Effects of Solutes. Solutes present in water will influence the radiation chemistry. Solutes present in high concentrations can react with the initially produced radicals and thereby prevent radical-radical reactions. This will change the $G$-values for the aqueous radiolysis products [7-9]. Solutes present in lower concentrations will not be able to compete with the radical-radical reactions, and therefore they will not influence the $G$-values. However, reactions between radicals and solutes will still lead to the formation of other reactive species $[4,5]$. This may also alter the redox conditions. In oxygen free aqueous solutions containing dissolved organic substances, the hydroxyl radical is usually converted to carbon-centered radicals that are either reductive or redox neutral in nature. In the presence of oxygen, carbon-centered radicals form peroxyl radicals that are oxidizing. For reducing carbon-centered radicals, the peroxyl radical formed upon reaction with oxygen can rapidly decompose producing superoxide. In the presence of $\mathrm{HCO}_{3}{ }^{-}$(e.g., in groundwater), the strongly oxidizing hydroxyl radical is converted to the slightly weaker oxidant $\mathrm{CO}_{3}{ }^{-}$. Hence, it is important to take the nature as well as the concentration of solutes into account when determining the final outcome of aqueous radiolysis.

2.3. Interfacial Radiation Chemistry. As stated before, radiation chemistry of water has been studied extensively for a very long time. However, from a practical point of view, the crucial processes in a nuclear technological installation (e.g., nuclear reactor, reprocessing plant, and repository for spent nuclear fuel) occur at the interface between water and a solid material. Nevertheless, very little is known about radiation-induced processes at the interface between solid materials and water [10]. To account for interfacial radiation chemistry, the reactivity of the aqueous radiolysis products towards solid surfaces must be known. It is also essential to understand the mechanism of energy deposition at the interface. The reactivity of radiolysis products towards some solid surfaces has now been studied [11], but still a large number of materials and systems remain to be investigated. Experimental studies performed during the last decade have shown that the $G$-value for $\mathrm{H}_{2}$ at the interface between some metal oxides and water differs considerably (higher) from the $G$-value in bulk water [12-15]. The magnitude of the discrepancy appears to depend on the type of oxide. However, the rationale for the observed discrepancy is not quite clear. It is interesting to note that no discrepancy has been reported for the other molecular radiolysis product, $\mathrm{H}_{2} \mathrm{O}_{2}$ [12].

The interaction between $\mathrm{H}_{2} \mathrm{O}_{2}$ and metal oxides has been studied to some extent in recent years [16-19]. In addition to the interaction with $\mathrm{UO}_{2}$ which will be described in more detail in this paper, the interaction between $\mathrm{H}_{2} \mathrm{O}_{2}$ and a number of metal oxides where the metal ion is in its highest oxidation state has been studied. In the majority of cases, it is clear that $\mathrm{H}_{2} \mathrm{O}_{2}$ is catalytically decomposed. The final product has been shown to be molecular oxygen, $\mathrm{O}_{2}$ [16]. The following mechanism for catalytic decomposition of $\mathrm{H}_{2} \mathrm{O}_{2}$ has been proposed:

$$
\begin{gathered}
\mathrm{H}_{2} \mathrm{O}_{2} \longrightarrow 2 \mathrm{HO}^{\bullet} \\
\mathrm{HO}^{\bullet}+\mathrm{H}_{2} \mathrm{O}_{2} \longrightarrow \mathrm{H}_{2} \mathrm{O}+\mathrm{HOO}^{\bullet} \\
\mathrm{HOO}^{\bullet}+\mathrm{HOO}^{\bullet} \longrightarrow \mathrm{H}_{2} \mathrm{O}_{2}+\mathrm{O}_{2}
\end{gathered}
$$

Very recently, the proposed mechanism was verified experimentally through the identification of the hydroxyl radical as a reaction intermediate [17]. This was done by adding Tris (tris(hydroxymethyl)aminomethane, $\left.\left(\mathrm{HOCH}_{2}\right)_{3} \mathrm{CNH}_{2}\right)$ to the system. Tris acts as a scavenger for hydroxyl radicals, and the product formed upon reaction with the hydroxyl radical is formaldehyde which can readily be quantified using UV-vis spectroscopy. Different oxides display different reactivity towards $\mathrm{H}_{2} \mathrm{O}_{2}$. This can, at least partly, be attributed to differences in adsorption energies for both $\mathrm{H}_{2} \mathrm{O}_{2}$ and the hydroxyl radical [19]. From kinetic studies, it is obvious that the reaction consists of two steps. The first step is adsorption of $\mathrm{H}_{2} \mathrm{O}_{2}$, and the second step is decomposition of adsorbed $\mathrm{H}_{2} \mathrm{O}_{2}$. In general, the adsorption is fairly rapid, while the decomposition is slower and usually becomes the rate limiting step. For some oxides, the second step is so fast that it is impossible to distinguish it from the first step. In addition, radiation chemical experiments have shown that hydroxyl radicals display affinity for oxide surfaces and that the affinity depends on the oxide. In these experiments, oxide powders in aqueous suspension have been shown to scavenge hydroxyl radicals in competition with Tris. The scavenging capacity was found to increase with increasing amount of oxide powder. Interestingly, density functional theory (DFT) calculations reproduce the relative affinity of the different oxides and also provide useful mechanistic insights concerning the catalytic decomposition of $\mathrm{H}_{2} \mathrm{O}_{2}$ [19]. DFT calculations have been crucial for the progress in this field. It should be emphasized that the interactions between aqueous radiolysis products and oxide surfaces are still far from being fully understood.

\section{Spent Nuclear Fuel}

Nuclear fuel can be considered to be pure $\mathrm{UO}_{2}$ in the form of pressed and sintered pellets. For light water reactors, the uranium must be enriched to $3-5 \%$ with respect to ${ }^{235} \mathrm{U}$ [5]. For heavy water reactors, natural uranium can be used [5]. During operation of a nuclear power reactor, heat is generated as a consequence of fission reactions occurring in the fuel. In this process, fissile materials are converted to lighter elements. In addition to fission products, transuranic elements are also formed upon neutron capture. The spent nuclear fuel can thus be considered as $\mathrm{UO}_{2}$ doped with fission products and transuranic elements. These dopants can exist as separate phases or as part of the $\mathrm{UO}_{2}$ matrix. Some 
of the fission products can form noble metal inclusions. Furthermore, the temperature gradients prevailing under operation will lead to formation of cracks.

The spent nuclear fuel is a highly radioactive material, and a large fraction of the radiation energy emitted from the radioactive fuel constituents will be absorbed by the fuel matrix itself. This will influence the properties of the material. In addition, recoils from alpha decay and fission reactions will induce distortion of the microstructure. Hence, spent nuclear fuel is a much more complex material than the unirradiated fresh nuclear fuel.

3.1. Radiation-Induced Dissolution of the Fuel Matrix in the Event of Groundwater Intrusion. One of the inherent beneficial properties of $\mathrm{UO}_{2}$ as a fuel matrix is the low solubility in anoxic groundwater [20, 21]. For this reason, the fuel matrix has sometimes been seen as a barrier in itself. However, as stated above, radiolysis of water produces oxidants as well as reductants that will alter the redox conditions at the fuel surface. Since it is quite difficult to reduce $\mathrm{UO}_{2}$, chemistry at the surface will be dominated by the radiolytic oxidants. $\mathrm{U}(\mathrm{IV})$ can be oxidized to $\mathrm{U}(\mathrm{VI})$ thereby the matrix solubility is considerably increased [20, 21 ]. Consequently, radiation-induced oxidative dissolution is a plausible route for the release of radionuclides. The release of radionuclides is congruent with the matrix dissolution. It should be noted that upon exposure to groundwater, there will be a rapid (instant) release of soluble fission products from the surface of the spent nuclear fuel. The dynamics of this process is very difficult to predict.

For the safety analysis, it is necessary to be able to predict the rate of radionuclide release caused by radiationinduced oxidative dissolution of the fuel matrix. This is the original source term in the safety analysis. Prediction of the release rate (or matrix dissolution rate) must be based on detailed knowledge about the following: geometrical dose distribution, radiation-induced chemistry (radiation chemistry) of the aqueous phase, kinetics of surface reactions (oxidation, reduction, adsorption, and dissolution), influence of groundwater components, and diffusion. As can be understood, this is quite an extensive task, and there is a vast body of the scientific literature covering this topic. Research on this topic has been summarized in several reviews [2123].

3.1.1. Geometrical Dose Distribution. The geometrical dose distribution (dose rate as a function of distance from fuel surface) depends on the radionuclide inventory of the spent nuclear fuel. To accurately calculate the geometrical dose distribution is not straight forward; but by using reasonable assumptions, fairly accurate estimates can be made. The necessary input data for this are concentration and decay energy of all relevant radionuclides in the fuel matrix. The inventory depends on fuel burnup and age. In general, the specific activity of the fuel matrix increases with burnup and decreases with age. The geometrical dose distribution is then estimated on the basis of geometry and self-shielding (most of the energy is absorbed within the fuel itself) [24]. As water
TABLE 1: Average alpha dose rate for different fuel ages and burnups [24].

\begin{tabular}{lcc}
\hline \multirow{2}{*}{ Fuel age (years) } & \multicolumn{2}{c}{ Dose rate $\left(\mathrm{Gy} \mathrm{s}^{-1}\right)$} \\
& $38 \mathrm{MWd} \mathrm{kg}^{-1}$ & $55 \mathrm{MWd} \mathrm{kg}^{-1}$ \\
\hline $10^{2}$ & $1.19 \times 10^{-1}$ & $1.71 \times 10^{-1}$ \\
$10^{3}$ & $2.87 \times 10^{-2}$ & $3.11 \times 10^{-2}$ \\
$10^{4}$ & $5.90 \times 10^{-3}$ & $6.06 \times 10^{-3}$ \\
$10^{5}$ & $5.44 \times 10^{-4}$ & $7.11 \times 10^{-4}$ \\
\hline
\end{tabular}

intrusion is not assumed to be a realistic scenario during the first 1000 years of the repository, a fuel age of at least 1000 years should be used in the safety analysis. In this scenario, the radiation field in the vicinity of the fuel surface will be dominated by alpha radiation [24]. As the maximum range of alpha particles in water is only around $40 \mu \mathrm{m}$, the major part of the solution will be exposed to beta and gamma radiation. However, the beta and gamma dose rates will be much lower than the alpha dose rate [24]. The average alpha dose rate for fuels of different age and two different burnups is given in Table 1.

3.1.2. Radiation Chemistry. As mentioned above, radiation chemistry of aqueous solutions has been studied extensively for more than half a century [4]. Radiolysis of water produces $\mathrm{HO}^{\circ}, \mathrm{H}^{\bullet}, \mathrm{e}_{\mathrm{aq}}{ }^{-}, \mathrm{HO}_{2}{ }^{\bullet}, \mathrm{H}_{2}$ and $\mathrm{H}_{2} \mathrm{O}_{2}$. The hydroxyl radical $(\mathrm{HO})^{\bullet}$, the hydroperoxyl radical $\left(\mathrm{HO}_{2}{ }^{\bullet}\right)$, and hydrogen peroxide $\left(\mathrm{H}_{2} \mathrm{O}_{2}\right)$ are oxidizing species, while the solvated (or hydrated) electron $\left(\mathrm{e}_{\mathrm{aq}}{ }^{-}\right)$, the hydrogen atom $\left(\mathrm{H}^{\bullet}\right)$ and hydrogen $\left(\mathrm{H}_{2}\right)$ are reducing species. The radiation chemical yields of these products are fairly well known, and it is possible to make accurate numerical simulations of homogeneous radiation chemistry of water. What makes the aqueous radiation chemistry a bit complex in the repository is the fact that there is a dose rate gradient and that several types of radiations are involved. These features must be accounted for.

3.1.3. Kinetics of Surface Reactions. Surface reactions constitute a key feature in the understanding of radiation-induced dissolution of spent nuclear fuel. The analysis of the kinetics for surface reactions has been described in more detail elsewhere $[10,25]$. Surface oxidation drives the dissolution of the $\mathrm{UO}_{2}$ matrix and the release of radionuclides. The solubility of $\mathrm{U}(\mathrm{VI})$ is enhanced by a number of complexing agents. In groundwater the most important complexing agent is $\mathrm{HCO}_{3}{ }^{-} / \mathrm{CO}_{3}{ }^{2-}$. It has been known for quite some time that the presence of $\mathrm{HCO}_{3}{ }^{-} / \mathrm{CO}_{3}{ }^{2-}$ enhances the rate of oxidative dissolution of $\mathrm{UO}_{2}$ considerably [21]. At low concentrations (less than $1 \mathrm{mM}$ ), the rate of oxidative dissolution is limited by the dissolution process; while at higher concentrations, the rate is governed by the oxidation process alone [26]. The $\mathrm{HCO}_{3}{ }^{-} / \mathrm{CO}_{3}{ }^{2-}$ concentration expected in groundwater of relevance in a granitic geological repository is in the order of $1-2 \mathrm{mM}$. Hence, the oxidation process will govern the 
dissolution of the spent nuclear fuel matrix. The mechanism is described in a simplistic way by the following reactions:

$$
\begin{gathered}
\mathrm{UO}_{2}(\mathrm{~s})+\mathrm{O} x \longrightarrow \mathrm{U}(\mathrm{VI})(\mathrm{s})+\text { Red } \\
\mathrm{U}(\mathrm{VI})(\mathrm{s}) \longrightarrow \mathrm{U}(\mathrm{VI})(\mathrm{aq})
\end{gathered}
$$

Although there are numerous studies on the dissolution of $\mathrm{UO}_{2}$ under oxidizing conditions [11,26-47], there are only a few studies on the kinetics of reactions between oxidizing radiolysis products and $\mathrm{UO}_{2}[11,26,46,47]$. In some early studies focused on uranium mining rather than on understanding the behavior of spent nuclear fuel, the reactivity of a number of oxidants towards $\mathrm{UO}_{2}$ was elucidated using electrochemical techniques [42]. In this early work, it was found that the rate constant for oxidation of $\mathrm{UO}_{2}$ is correlated to the standard reduction potential of the oxidant. On the basis of more recent experiments performed using powder suspensions, it was confirmed that the rate constants for $\mathrm{UO}_{2}$ oxidation by aqueous radiolysis products depend on the standard reduction potential [11, 26]. This relationship was used to estimate the rate constants for some of the short-lived radical products that are difficult to study experimentally. Hence, a set of rate constants for oxidation of $\mathrm{UO}_{2}$ is now available. Oxidation of $\mathrm{UO}_{2}$ by the most reactive radicals, $\mathrm{OH}^{\bullet}$ and $\mathrm{CO}_{3}{ }^{-}$, was found to be diffusion controlled. It is interesting to note that the limit for diffusion control is considerably lower for a heterogeneous system compared to a homogeneous system. As a consequence, the difference in surface reactivity of $\mathrm{H}_{2} \mathrm{O}_{2}$ and the most reactive radical species is fairly small (less than two orders of magnitude) $[10,11,26]$. For homogeneous bimolecular reactions in solution, the corresponding difference in reactivity is several orders of magnitude.

The set of rate constants was used to simulate the dissolution of uranium in $\mathrm{UO}_{2}$ powder suspension exposed to $\gamma$-radiation [48]. The same system was also studied experimentally [49]. In the simulation, the homogeneous radiation chemistry of the aqueous solution was numerically simulated, and the resulting oxidant concentrations were used in combination with the corresponding rate constants for oxidation of $\mathrm{UO}_{2}$ using

$$
\frac{d n_{\mathrm{U}(\mathrm{VI})}}{d t}=A_{\mathrm{UO}_{2}} \sum_{\mathrm{O} x=1}^{n} k_{\mathrm{O} x}[\mathrm{O} x] \frac{n_{\mathrm{e}^{-}}}{2},
$$

where $A_{\mathrm{UO}_{2}}$ is the surface area of the solid $\mathrm{UO}_{2}, k_{\mathrm{Ox}}$ is the rate constant of a given oxidant, $[\mathrm{Ox}]$ is the oxidant concentration, and $n_{\mathrm{e}^{-}}$is the number of electrons involved in the redox process $\left(2\right.$ for $\mathrm{H}_{2} \mathrm{O}_{2}$ and $\mathrm{O}_{2}$ and 1 for the oxidizing radicals). This approach can be used as long as the surface reactions do not significantly influence the bulk concentrations in solution. Hence, for extremely high solid surface area to solution volume ratios, this approach is not valid. The result from the simulation was almost a perfect match with the experimental result [48]. On the basis of these promising results, further simulations for both $\gamma$ - and $\alpha$-radiolysis were performed, and it was shown that, under repository conditions, the dominating oxidant is $\mathrm{H}_{2} \mathrm{O}_{2}$ [48]. The relative impact of $\mathrm{H}_{2} \mathrm{O}_{2}$ turned out to be very close to
$100 \%$. This simplifies the analysis of radiation-induced spent nuclear fuel dissolution considerably, as only one oxidant needs to be considered for the oxidation of $\mathrm{UO}_{2}$. However, it is important to keep in mind that these results were obtained for pure $\mathrm{UO}_{2}$, not for real spent nuclear fuel.

Given the findings presented earlier, it is essential to investigate the effects of the presence of fission products and transuranic elements in the $\mathrm{UO}_{2}$ matrix. A number of studies have been performed on real spent nuclear fuel $[21,50]$, but, due to the complexity of the material and the practical difficulties connected to the handling of highly radioactive material, it is virtually impossible to analyze the effects of single constituents. This can be circumvented by producing $\mathrm{UO}_{2}$ pellets doped with one or a few well-defined constituents. Several different types of materials have been manufactured and tested in dissolution experiments. $\mathrm{UO}_{2}$ doped with $\alpha$-emitting nuclides [51-58] has been used to mimic the radiation field from spent nuclear fuel older than 1000 years. $\mathrm{UO}_{2}$ has been doped with $\mathrm{Pd}$ particles $[59,60]$ to mimic the effect of $\varepsilon$-phase particles (fission products forming noble metal inclusions in the fuel matrix) and with rare earth oxides [61-63] to mimic the effect of fission products forming oxides in the fuel matrix. SIMFUEL is a more complex material produced to mimic some of the chemical properties of spent nuclear fuel. In SIMFUEL, 11 nonradioactive isotopes of fission products have been added to the $\mathrm{UO}_{2}$ matrix. Experiments using $\mathrm{UO}_{2}$ pellets doped with Pd particles clearly show that the rate of oxidation is catalyzed by the presence of Pd particles [60]. This can be seen in experiments where the pellets are exposed to $\mathrm{H}_{2} \mathrm{O}_{2}$ or $\mathrm{O}_{2}$ in aqueous solution but also in experiments where the pellet immersed in aqueous solution is exposed to $\gamma$-radiation. The Pd-catalyzed reaction appears to be diffusion controlled [60]. The effect of rare earth oxide doping is more complex. When exposing pellets to $\mathrm{H}_{2} \mathrm{O}_{2}$ in aqueous solution, very small differences in the rate of oxidant consumption are observed [61-64]. However, the rate of uranium release from the pellets differs considerably. For the pellets doped with rare earth oxides (including SIMFUEL), the rate of uranium release is considerably lower than that of the pure $\mathrm{UO}_{2}$ pellets [61-64]. As previously mentioned, $\mathrm{H}_{2} \mathrm{O}_{2}$ can react in two different ways on an oxide surface. $\mathrm{H}_{2} \mathrm{O}_{2}$ can either oxidize the surface or undergo catalytic decomposition. The change in uranium dissolution observed for the doped $\mathrm{UO}_{2}$ is attributed to a change in the ratio of the rates between these two possible reactions. It is clear that the impact of the catalytic decomposition increases with doping. On simple kinetic grounds, the observed increase cannot be attributed to the reactivity of the dopant alone but rather a change in reactivity of the doped material. In a recent study, the catalytic decomposition and the oxidation of $\mathrm{UO}_{2}$ were studied separately for a number of doped and undoped $\mathrm{UO}_{2}$-based materials including SIMFUEL [63]. In this study, oxidants that cannot undergo catalytic decomposition were used in addition to $\mathrm{H}_{2} \mathrm{O}_{2}$. The results show that there is a relatively small difference in the rate of catalytic $\mathrm{H}_{2} \mathrm{O}_{2}$ decomposition for the different materials. It is interesting to note that the hydroxyl radicals formed at the doped $\mathrm{UO}_{2}$ surface upon decomposition of $\mathrm{H}_{2} \mathrm{O}_{2}$ are possible to 
be scavenged by Tris. Considering the standard reduction potential, the hydroxyl radical should rapidly oxidize the surface. The fact that this does not happen indicates that the redox reaction and the catalytic decomposition of $\mathrm{H}_{2} \mathrm{O}_{2}$ occur at different surface sites. Furthermore, the fact that the rate of catalytic decomposition does not appear to vary with doping implies that the catalytic sites are not significantly influenced by doping. The redox reaction, on the other hand, is strongly dependent on doping. The experiments show that the difference in redox reactivity between doped and undoped $\mathrm{UO}_{2}$ can mainly be attributed to a difference in the activation energy of the reaction [63]. Consequently, the observed difference is due to a true change in reactivity and not simply due to a change in the number of redox reactive sites. This also implies that the relative impact of the different oxidants produced from radiolysis of water will change when going from pure $\mathrm{UO}_{2}$ to a doped material resembling spent nuclear fuel [63]. In this case, radicals will become more important. This is an issue that needs to be studied further as the reasons behind the change in redox reactivity of the surface are not well understood.

Under conditions where the solubility of uranium is limited, secondary phases may be formed on the surface of the spent nuclear fuel [21]. This will alter the chemistry of fuel dissolution considerably. The secondary phase could protect the surface from further oxidation and dissolution, but it could also provide local conditions facilitating corrosion. However, under the conditions expected in a granitic geological repository, formation of secondary phases on the fuel surface is expected to be of minor importance.

3.1.4. Influence of Groundwater Components. The effect of one of the major groundwater constituents, $\mathrm{HCO}_{3}{ }^{-} / \mathrm{CO}_{3}{ }^{2-}$, has already been discussed. In addition to the enhanced solubility of $\mathrm{U}(\mathrm{VI}), \mathrm{HCO}_{3}{ }^{-} / \mathrm{CO}_{3}{ }^{2-}$ can also be converted to $\mathrm{CO}_{3}{ }^{--}$upon reaction with the hydroxyl radical. There are numerous other constituents that could also influence the process of radiation-induced oxidative dissolution [6567]. A few of these constituents will be discussed here. Groundwater usually contains low concentrations of sulfide and iron. Sulfide has been shown to react with $\mathrm{H}_{2} \mathrm{O}_{2}$ and other radiolytic oxidants and also to reduce $\mathrm{U}(\mathrm{VI})$ to $\mathrm{U}(\mathrm{IV})$. Considering the low concentrations of sulfide expected in a repository, these effects are considered to be of marginal importance [67]. The main effect is probably that sulfide will scavenge a small fraction of the radiolytic oxidants and thereby reduce the rate of matrix dissolution to some extent. Iron (Fe(II)) will also be able to scavenge radiolytic oxidants, and since $\mathrm{Fe}(\mathrm{II})$ is more reactive towards $\mathrm{H}_{2} \mathrm{O}_{2}$, the impact of iron is expected to be larger. Simulations have shown that $10 \mu \mathrm{M} \mathrm{Fe}{ }^{2+}$ in the groundwater will reduce the rate of matrix dissolution by at least one order of magnitude [65]. The presence of various organic substances (e.g., humic substances) will also reduce the rate of oxidation, mainly by scavenging the oxidizing radical species formed upon radiolysis of water.

Hydrogen, $\mathrm{H}_{2}$, is produced by radiolysis and also in anaerobic corrosion of iron. Given the amount of iron present in the canister, very large amounts of $\mathrm{H}_{2}$ can be produced upon canister failure. Consequently, $\mathrm{H}_{2}$ can be one of the main groundwater constituents in a failed canister. In general, $\mathrm{H}_{2}$ is a slow reductant that requires a catalyst to become efficient. $\mathrm{H}_{2}$ can influence the process of radiationinduced oxidative dissolution in a deep repository in several different ways. First of all, $\mathrm{H}_{2}$ present in water will influence the radiation chemistry [68]. $\mathrm{H}_{2}$ reacts with the hydroxyl radical and forms a hydrogen atom which, in turn, can react with $\mathrm{H}_{2} \mathrm{O}_{2}$. In the latter reaction, a new hydroxyl radical is formed. Hence, $\mathrm{H}_{2}$ drives a chain reaction that consumes $\mathrm{H}_{2} \mathrm{O}_{2}$ [4]. This will reduce the rate of matrix dissolution. It should be noted that this process will not be able to completely stop the oxidative dissolution [68]. It is important to note that the magnitude of the effect of $\mathrm{H}_{2}$ on the radiolytic production of $\mathrm{H}_{2} \mathrm{O}_{2}$ depends on other solutes as well. The reason for this is that the hydroxyl radical reaction with hydrogen will compete with other possible reactions for the hydroxyl radical. In the presence of high concentrations of $\mathrm{HCO}_{3}{ }^{-}$, the hydroxyl radical will preferentially react with $\mathrm{HCO}_{3}{ }^{-}$and produce $\mathrm{CO}_{3}{ }^{--}$. $\mathrm{CO}_{3}{ }^{--}$will not react with $\mathrm{H}_{2}$, and therefore, the decomposition of $\mathrm{H}_{2} \mathrm{O}_{2}$ will be suppressed. In systems containing $\mathrm{HCO}_{3}{ }^{-}$, considerably higher $\mathrm{H}_{2}$ concentrations are required to see an effect.

It has also been shown that $\mathrm{H}_{2}$ can reduce $\mathrm{U}(\mathrm{VI})$ to $\mathrm{U}(\mathrm{IV})$ in solution [69]. This process is very slow, and it will not contribute to inhibition of the radionuclide release. The process becomes much faster in the presence of a catalyst, such as Pd particles [70]. Electrochemical experiments have shown that the corrosion potential of SIMFUEL containing noble metal inclusions drops drastically in the presence of $\mathrm{H}_{2}$ [71]. On the basis of this observation a reaction where the noble metal inclusions catalyze the reduction of $\mathrm{U}(\mathrm{VI})$ to $\mathrm{U}(\mathrm{IV})$ by $\mathrm{H}_{2}$ on the surface of the pellet was postulated [71]. This reaction was later verified using $\mathrm{Pd}$ particle-doped $\mathrm{UO}_{2}$ pellets exposed to $\mathrm{H}_{2} \mathrm{O}_{2}$ and $\mathrm{H}_{2}$ [59]. In these experiments, $\mathrm{Pd}$-doped pellets with different $\mathrm{Pd}$ concentrations were exposed to aqueous solutions containing $\mathrm{H}_{2} \mathrm{O}_{2}$ and $\mathrm{HCO}_{3}{ }^{-}$at different partial pressures of $\mathrm{H}_{2}$. The rate of uranium dissolution was measured in each case. From these experiments, the rate constant for this process could also be extracted. It is clear that this reaction can completely suppress the oxidative dissolution of the matrix and prevent release of radionuclides. This has been verified in experiments using real spent nuclear fuel [72]. In this series of spent nuclear fuel leaching experiments, sealed ampoules were used, and no $\mathrm{H}_{2}$ was added from the beginning. The only source of hydrogen was radiolysis of water. Interestingly, the experiments showed that the amount of hydrogen produced from radiolysis of water under these conditions becomes sufficient to completely inhibit radiation-induced dissolution of spent nuclear fuel after some time. The most relevant surface processes involved in radiation-induced dissolution of the spent nuclear fuel matrix are illustrated in Figure 2.

3.1.5. A Practical Approach. Simulation of radiation-induced dissolution of spent nuclear fuel under deep repository conditions is a very complex operation if all processes and 


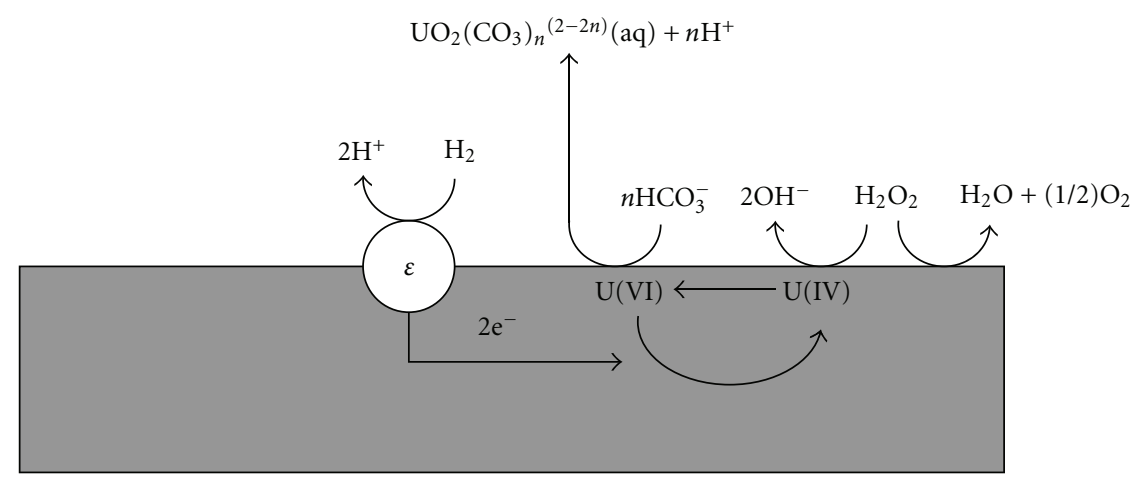

FIGURE 2: Schematic overview of the most important surface processes in radiation-induced dissolution of spent nuclear fuel.

parameters are to be included. It is therefore, very valuable to use simplified, yet accurate, models. Several attempts to simulate the system have been made, and in many cases, rate constants and even reactions have been based on assumptions rather than experimental evidence. This has been discussed in depth in a recent review [23]. The following is a short description of a fairly simple practical approach to solve the problem.

As was previously shown, $\mathrm{H}_{2} \mathrm{O}_{2}$ is the oxidant dominating the surface oxidation of $\mathrm{UO}_{2}$. The relative impact of $\mathrm{H}_{2} \mathrm{O}_{2}$ was found to be $99.9 \%$ or more under conditions relevant in a deep repository [48]. Consequently, we can focus our attention on $\mathrm{H}_{2} \mathrm{O}_{2}$ without reducing the accuracy in our predictions. Keeping in mind that we have continuous irradiation of the aqueous phase in our system, we can make further simplifications. In any system where there is a constant rate of production of species and the species produced can also be consumed in one or several reactions, the concentration of the species in question will increase until we reach a point where the rate of production is balanced by the rate of consumption. At this point, the concentration will reach a constant value, and we can use a steady-state approximation to describe the kinetics of the system. Radiation-induced dissolution of spent nuclear fuel is a typical case where the steady-state approximation should be applied. The only question is how long it takes before a steady-state concentration of $\mathrm{H}_{2} \mathrm{O}_{2}$, is reached. This problem has been addressed in some previous papers where the system was simulated taking the geometrical dose distribution, the radiolytic production of $\mathrm{H}_{2} \mathrm{O}_{2}$, the surface reaction consuming $\mathrm{H}_{2} \mathrm{O}_{2}$ and diffusion of $\mathrm{H}_{2} \mathrm{O}_{2}$ into account $[65,73,74]$. Interestingly, the results of the simulations showed that the surface concentration of $\mathrm{H}_{2} \mathrm{O}_{2}$ approaches the steady-state level within a matter of seconds to minutes, even though the bulk concentration is much lower. Consequently, we can use the steady-state approach to simulate radiation-induced dissolution of spent nuclear fuel. The relationship describing the rate of $\mathrm{H}_{2} \mathrm{O}_{2}$ production and thereby also the rate of $\mathrm{H}_{2} \mathrm{O}_{2}$ consumption at steady-state is given in

$$
r_{\mathrm{H}_{2} \mathrm{O}_{2}}=\int_{x=0}^{x_{\max }} \dot{D}(x) \times \rho \times G\left(\mathrm{H}_{2} \mathrm{O}_{2}\right) d x .
$$

In (7), $\dot{D}(x)$ is the dose rate at distance $x$ from the fuel surface, $\rho$ is the density of water, and $G\left(\mathrm{H}_{2} \mathrm{O}_{2}\right)$ is the radiation chemical yield for $\mathrm{H}_{2} \mathrm{O}_{2}$. To obtain the production rate the function must be integrated from 0 to the maximum range of the alpha radiation. Alternatively, the average dose rate, and the maximum range of alpha radiation can be used to avoid integration. When comparing results from simple simulations using the steady-state approach with experimental results, it is obvious that the agreement is quite good $[72,75]$. It is even possible to account for the inhibiting effect of $\mathrm{H}_{2}$ (catalyzed by noble metal inclusions) in a relatively simple way using

$$
r_{\mathrm{O} x}=r_{\mathrm{H}_{2} \mathrm{O}_{2}}-k_{\mathrm{H}_{2}}\left[\mathrm{H}_{2}\right] \varepsilon_{\text {rel }} \text {. }
$$

In (8), $r_{\mathrm{O} x}$ denotes the rate of oxidative matrix dissolution, $k_{\mathrm{H}_{2}}$ is the rate constant for the reaction between dissolved $\mathrm{H}_{2}$ and the noble metal inclusions (diffusion controlled), and $\varepsilon_{\text {rel }}$ is the relative surface fraction covered with noble metal particles. When doing this, the effect of $\mathrm{H}_{2}$ on real spent nuclear fuel dissolution is also accurately reproduced. The main problem with this approach is that it tends to overestimate the rate of dissolution (in the absence of $\mathrm{H}_{2}$ ). This is good from a safety analysis perspective. The rationale for the overestimation is simply that the catalytic decomposition of $\mathrm{H}_{2} \mathrm{O}_{2}$ is not accounted for. However, this can easily be included if the ratio between the rate constants for oxidation and catalytic decomposition is known. Solution reactions consuming radiolytic oxidants are more difficult to account for using this simple approach. However, simple methods accounting for solution reactions have also been proposed [65].

\section{Copper Canister}

Corrosion of copper under anaerobic conditions has been debated quite vigorously during the past decade [76-79]. There is still a controversy on this issue, but ongoing experiments will hopefully resolve this.

The dose rate at the surface of the canister will be in the order of $1 \mathrm{~Gy} \mathrm{~h}^{-1}$ ( ca $3 \times 10^{-4} \mathrm{~Gy} \mathrm{~s}^{-1}$ ) when the canisters are placed in the repository. For comparison, this dose rate is about three orders of magnitude lower than the dose rates at the surface of the spent nuclear fuel when the 


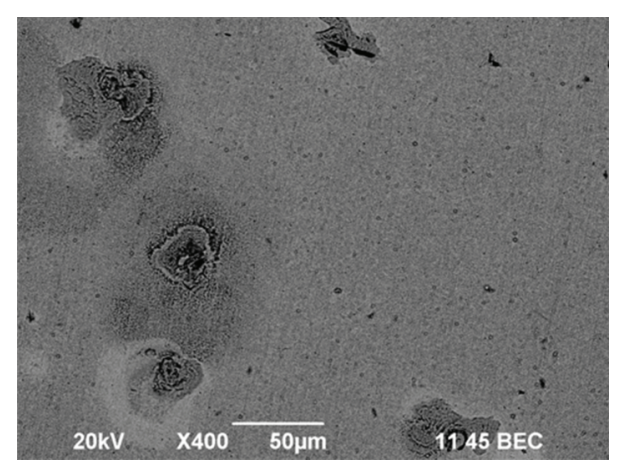

FIGURE 3: SEM image of copper irradiated for $168 \mathrm{~h}$ at a dose rate of $0.21 \mathrm{~Gy} \mathrm{~s}^{-1}$ in deoxygenated water.

fuel is 100 years old. The main contributor to the gamma dose is Cs-137 which has a half-life of around 30 years. Consequently, the gamma dose rate at the copper surface will decrease by $50 \%$ every 30 years. Nevertheless, water in contact with the canister will undergo radiolysis resulting in the formation of radiolysis products as described previously. The standard reduction potentials of the hydroxyl radical and hydrogen peroxide are higher than the potential for copper- and radiation-induced corrosion of copper is thus a thermodynamically feasible process. However, studies on radiation-induced corrosion of copper have been scarcely reported in the scientific literature [80-86]. Some studies have indicated that ionizing radiation increases the rate of corrosion of copper in contact with water, while other studies do not show any radiation effect. In a relatively recent study [87], a considerable increase in copper corrosion rate was observed upon exposure to gamma radiation. The corrosion rate was quantified in terms of release of copper to the aqueous phase. Furthermore, a relatively unusual corrosion pattern was observed (Figure 3) [87].

The local corrosion features consist of holes where the surface is mainly covered with cuprite surrounded by a circular area where the surface consists mainly of pure copper. Outside the circular area of copper, the surface is also covered with cuprite. These local corrosion features were studied using SEM, AFM, and confocal Raman spectroscopy. The Raman spectroscopy studies were performed to obtain local characterization of the corrosion products, and AFM was used to provide information about the topology of the local corrosion features. According to the latter studies, the depth of the central cavity of the local corrosion feature is in the order of $1 \mu \mathrm{m}$ [87]. Even more recent studies [88] have shown that the release of copper to the aqueous solution depends on the total radiation dose. Interestingly, a relatively high dose is required before dissolved copper can be detected using ICP-OES. This could partly explain why some papers have reported that radiation induces corrosion of copper, while other papers have reported the opposite. There is a relatively large difference in the total doses used in the different studies. However, above the detection limit, the copper concentration appears to increase linearly with dose. It should be noted that copper oxide at the surface must also be included in total mass balance. This information is not yet available.

As was discussed for the oxidation of spent nuclear fuel, it is possible to obtain the concentrations of radiolytic oxidants from numerical simulations of homogeneous radiation chemistry in water. The oxidant concentrations in solution in combination with the rate constants for oxidation of copper can be used to calculate the total rate of corrosion (according to (6)). As the rate constants for the reactions with copper are not yet known, the highest possible rate constants (corresponding to a diffusioncontrolled reaction with no activation barrier) can be used. This will provide the maximum rate of oxidation that can be attributed to aqueous radiation chemistry. Such a simulation was recently performed for the copper system, and the results were somewhat surprising [88]. It is clear that the simulations underestimate the release of copper by almost two orders of magnitude. Keeping in mind that the simulations represent an unrealistic maximum corrosion rate and the fact that corrosion products present in the oxide layer are not accounted for, it can easily be realized that the discrepancy is expected to be even larger than two orders of magnitude. This strongly contradicts the $\mathrm{UO}_{2}$ system where an almost perfect match between experimental results and the calculations based on homogeneous radiation chemistry was observed. It should be noted that, in the experiments, copper release due to irradiation is always compared to a reference sample where copper is exposed to the same solution for the same time but in the absence of ionizing radiation. This implies that a completely different process is responsible for the radiation-induced corrosion of copper. This is a field where considerably more work is needed before the process can be fully understood.

It is important to note that even if the process of radiation-induced corrosion of copper does not turn out to be a serious threat to the integrity of the canister, the susceptibility of the corroded surface to other groundwater components needs to be elucidated. The interaction between the corroded surface and bentonite is of particular importance.

\section{The Bentonite Barrier}

Bentonite clay is a natural material, and the composition depends on its origin. The main constituent of bentonite is montmorillonite (a 2:1 phyllosilicate mineral with one dioctahedral sheet sandwiched between two tetrahedral sheets [89]) which is formed from alteration of volcanic ash. In addition to the montmorillonite, bentonite also contains a range of accessory minerals and organic matter. Montmorillonite has two properties of particular importance when using the material as a barrier in a repository for spent nuclear fuel: (1) montmorillonite swells upon uptake of water, and (2) montmorillonite has high affinity for cations. The latter explains why the bentonite barrier provides efficient retention of radionuclides escaping from a damaged canister. The swelling of the clay prevents free water from reaching the canister, rendering diffusion through the clay 
barrier as the only possible option for radionuclide transport from the canister.

In a repository, bentonite will be exposed to gammaand neutron radiations even when the canister is intact. The maximum dose rate will be the same as for the copper surface of the canister. The total $\gamma$-dose will be in the order of 40 $200 \mathrm{kGy}$. For this reason, it is important to elucidate the effect of ionizing radiation on the barrier properties of bentonite. This has been studied to some extent. Several studies have investigated $\gamma$-radiation effects on bentonite at low water content [90-94]. Even at very high doses of several MGy, only small or insignificant effects have generally been found on both physical and chemical properties of bentonite and montmorillonite.

\subsection{Radiation Effects on the Redox Properties of Montmoril-} lonite. The structural content of iron in montmorillonite provides a basis for alteration of the redox properties upon exposure to radiation. Iron can be present as $\mathrm{Fe}(\mathrm{II})$, and $\mathrm{Fe}(\mathrm{III})$ and the ratio between the two oxidation states will determine the redox properties. The ratio between the two oxidation states can also change the surface charge which could result in changed sorption properties as well as changed stability for colloids produced from montmorillonite. In a recent study [95], the reactivity of $\gamma$-irradiated montmorillonite towards $\mathrm{H}_{2} \mathrm{O}_{2}$ was investigated. $\mathrm{H}_{2} \mathrm{O}_{2}$ is a radiolysis product which is involved in radiation-induced corrosion of copper. Hence, the reactivity of montmorillonite towards $\mathrm{H}_{2} \mathrm{O}_{2}$ is also of importance for the integrity of the canister.

Experiments performed under anoxic conditions showed that the reactivity of montmorillonite towards $\mathrm{H}_{2} \mathrm{O}_{2}$ increases with $\gamma$-dose and with clay concentration. Determinations of the ratio between $\mathrm{Fe}$ (II) and $\mathrm{Fe}$ (III) show that the $\mathrm{Fe}$ (II) content increases with dose up to $6.5 \mathrm{kGy}$ [95]. At higher doses, no further increase in $\mathrm{Fe}(\mathrm{II})$ content is observed under these conditions. This can probably be attributed to a steady-state situation where the rate of $\mathrm{Fe}(\mathrm{III})$ reduction is balanced by the rate of $\mathrm{Fe}(\mathrm{II})$ oxidation. It is also clear that exposure to $\mathrm{H}_{2} \mathrm{O}_{2}$ after irradiation decreases the $\mathrm{Fe}(\mathrm{II})$ content. The same type of experiments was also performed under reducing conditions, that is, the irradiation of the clay was performed in the presence of 2-propanol which scavenges the strongly oxidizing hydroxyl radical and forms a reducing radical. Under reducing conditions, the effect of irradiation is more pronounced, and steady-state is not reached. $\mathrm{Fe}(\mathrm{III})$ is almost completely converted to $\mathrm{Fe}(\mathrm{II})$ at $13 \mathrm{kGy}$. Upon repeated exposure to $\mathrm{H}_{2} \mathrm{O}_{2}$, the ratio between $\mathrm{Fe}(\mathrm{II})$ and $\mathrm{Fe}(\mathrm{III})$ returns to the original value corresponding to unirradiated montmorillonite. It is also clear that the amount of $\mathrm{H}_{2} \mathrm{O}_{2}$ that can be consumed by montmorillonite depends on $\gamma$ dose. Hence, there is a strong correlation between radiation-induced changes in redox properties of montmorillonite and the ratio between $\mathrm{Fe}(\mathrm{II})$ and $\mathrm{Fe}(\mathrm{III})$. The reducing conditions used in the experiments could be relevant in a deep repository since natural bentonite contains organic matter. It is interesting to note that irradiated bentonite clay will react with one of the main radiolysis products and thereby potentially protect the canister from radiation-induced corrosion.

\subsection{Radiation Effects on Radionuclide Retention in Com-} pacted Bentonite. One of the most important properties of montmorillonite as a barrier is the capacity to adsorb cations. Adsorption of cations will slow down the process of diffusion through the compacted bentonite barrier and thereby contribute to the retention of radionuclides escaping from a failed canister. Hence, it is crucial to investigate the possible effects of radiation on the adsorption capacity of montmorillonite and bentonite. In a recent study, the radiation effects on both adsorption and diffusion were investigated experimentally [96].

The adsorption studies were performed using batch adsorption experiments where the radionuclide concentration in the aqueous phase is measured after equilibration with montmorillonite. Irradiation of montmorillonite was performed under different conditions. The diffusion experiments were performed using diffusion cells where the clay is compacted to different extents. The clay samples were irradiated in compacted form.

The adsorption studies showed that the affinity for $\mathrm{Co}^{2+}$ decreased significantly upon irradiation. This effect was observed for clay samples irradiated in dry, as well as wet, state which indicates that this could be attributed to a direct effect rather than an indirect effect. A direct effect means that the radiation energy is directly absorbed by the clay, while an indirect effect refers to radiation energy absorbed by water followed by reactions between aqueous radiolysis products and the clay. For the more weakly sorbing $\mathrm{Cs}^{+}$, no significant difference in affinity was observed upon irradiation.

The diffusion experiments did not reveal any significant effect of radiation. However, the uncertainty of this type of experiment is too large to be able to observe an effect attributed to the difference in $\mathrm{Co}^{2+}$ adsorption stated earlier.

\subsection{Radiation Effects on the Stability of Colloidal Montmoril-} lonite Dispersions. When in contact with water, the bentonite may disperse into colloidal particles. This process is of particular importance if water with low ionic strength such as glacial melting water reaches the compacted bentonite. Dispersion of compacted bentonite will deteriorate the barrier properties, and the formation of bentonite colloids may even facilitate radionuclide transport. The mobility of the colloids depends on the colloidal stability which in turn depends on $\mathrm{pH}$, ionic strength, and temperature. These effects have been studied quite extensively [97-100]. However, in a deep repository, the bentonite colloids may also be exposed to ionizing radiation. For this reason it is important to elucidate the effect of ionizing radiation on the colloid stability. A series of experiments has been performed in order to study the radiation effects [101]. Measurements of the colloid concentration as a function of time using photon correlation spectroscopy (PCS) showed that the stability is higher for irradiated colloidal suspensions at elevated ionic strength, that is, the unirradiated colloidal suspension is more sensitive to changes in the ionic strength 
than the irradiated colloidal suspension. Sedimentation experiments revealed the same trend, that is, sedimentation was slower for the irradiated suspensions when increasing the ionic strength. The sedimentation volume for the irradiated samples was larger than for the unirradiated samples. Again, this indicates that ionizing radiation increases the stability of the colloids. It was also clear that the ionic strength required to induce sedimentation increases with increasing, radiation dose up to about $27 \mathrm{kGy}$. Interestingly, the ionic strength required to induce sedimentation also increased with increasing concentration of irradiated clay at a given dose. This indicates that the effect is not a direct radiation effect. Above a dose of $27 \mathrm{kGy}$, no further increase in stability could be observed. In general, the effects described here are attributed to increased surface potential upon irradiation. This was verified in experiments where the liquid phase was removed and replaced after irradiation. The observed effect of irradiation persists even after replacing the liquid phase.

5.4. Summary of Radiation Effects on Bentonite. The rationale for the different radiation effects discussed before is somewhat contradictory. The effect on the redox properties of montmorillonite is attributed to an increase in the $\mathrm{Fe}$ (II) to $\mathrm{Fe}(\mathrm{III})$ ratio. The effect on the adsorption properties of montmorillonite is attributed to a change in surface potential or charge. This implies a change towards a less negative potential. Finally, the change in colloidal stability is attributed to a change in surface potential towards a higher potential. If any effect, the change in $\mathrm{Fe}$ (II) to $\mathrm{Fe}$ (III) ratio upon irradiation would increase the negative surface potential. This is in line with the observed change in colloid stability. The contradictory conclusion would then be that for the radiation effect on cation adsorption. However, $\mathrm{Co}^{2+}$ is a strongly sorbing cation that binds to specific sites. In this process, the surface potential may be of minor importance, and the rationale could simply be that radiation alters the specific sites for adsorption. Some of the observed effects appear to be due to direct effects of ionizing radiation, while other effects appear to be due to indirect effects. Clearly, further studies are needed to clarify the nature of these effects.

\section{Future Research Needs}

The processes described previously are all examples of interfacial radiation chemistry. This is a field where fundamental knowledge is still very scarce, and considerable research efforts are needed. It is clear that even for a relatively simple material as copper, radiation-induced surface processes are poorly understood. Hence, basic research on interfacial radiation chemistry is a necessity for further development in nuclear technology. One interesting way of pursuing this research is by studying radiation chemistry of confined systems where a porous solid material is used.

From a more applied point of view, research under more realistic conditions using materials resembling the materials of practical importance needs to be continued and further developed. Even though the process of radiation-induced dissolution of $\mathrm{UO}_{2}$ appears to be fairly well understood, it is important to understand the effects of features that are present in real spent nuclear fuel. The effects of dopants present as oxides or metallic inclusions and combinations of dopants must be further explored. Effects of microstructure are also important. The chemical conditions in a narrow crack are not necessarily the same as on a surface exposed to an aqueous phase. Other types of fuel, for example, MOX, also need to be studied in more detail.

As shown in this paper, radiation-induced corrosion of copper cannot be explained by aqueous radiation chemistry alone. This process needs to be studied further, and similar studies on other metallic materials should also be performed to shed some light on the nature of this type of process.

The origin of the radiation effects on the bentonite is not clear. Bentonite is a complex material, and the composition depends on the origin of the clay. For this reason, it is important to use pure montmorillonite when exploring the nature of the radiation effects. As there are two types of montmorillonites, $\mathrm{Na}^{+}$and $\mathrm{Ca}^{2+}$ montmorillonite, radiation effects on both types should be studied in more detail.

\section{Acknowledgments}

The author is grateful to the Swedish Nuclear Fuel and Waste Management Company (SKB) for financial support of a significant part of the work on which this paper is based. The author also thanks all the coauthors of the papers on which this paper is based.

\section{References}

[1] http://www.skb.se/.

[2] http://www.posiva.fi/.

[3] http://www.ssm.se/.

[4] J. W. T. Spinks and R. J. Woods, An Introduction to Radiation Chemistry, John Wiley \& Sons, New York, NY, USA, 3rd edition, 1990.

[5] G. Choppin, J. O. Liljenzin, and J. Rydberg, Radiochemistry and Nuclear Chemistry, Reed Educational and Professional Publishing, Oxford, UK, 1995.

[6] J. F. Wishart and B. S. M. Rao, Eds., Recent Trends in Radiation Chemistry, World Scientific, River Edge, NJ, USA, 2010.

[7] B. Pastina and J. A. LaVerne, "Scavenging of the precursor to the hydrated electron by the selenate ion," Journal of Physical Chemistry A, vol. 103, no. 1, pp. 209-212, 1999.

[8] B. Pastina, J. A. LaVerne, and S. M. Pimblott, "Dependence of molecular hydrogen formation in water on scavengers of the precursor to the hydrated electron," Journal of Physical Chemistry A, vol. 103, no. 29, pp. 5841-5846, 1999.

[9] I. Stefanic and J. A. LaVerne, "Temperature dependence of the hydrogen peroxide production in the $\gamma$-radiolysis of water," Journal of Physical Chemistry A, vol. 106, no. 2, pp. 447-452, 2002.

[10] M. Jonsson, "Radiation induced processes at solid-liquid interfaces," in Recent Trends in Radiation Chemistry, J. F. Wishart and B. S. M. Rao, Eds., pp. 301-323, World Scientific, River Edge, NJ, USA, 2010.

[11] E. Ekeroth and M. Jonsson, "Oxidation of $\mathrm{UO}_{2}$ by radiolytic oxidants," Journal of Nuclear Materials, vol. 322, no. 2-3, pp. 242-248, 2003. 
[12] J. A. LaVerne and L. Tandon, " $\mathrm{H}_{2}$ production in the radiolysis of water on $\mathrm{CeO}_{2}$ and $\mathrm{ZrO}_{2}$," Journal of Physical Chemistry B, vol. 106, no. 2, pp. 380-386, 2002.

[13] J. A. LaVerne and S. E. Bonnies, " $\mathrm{H}_{2}$ production in the radiolysis of aqueous $\mathrm{SiO}_{2}$ suspensions and slurries," Journal of Physical Chemistry B, vol. 107, no. 30, pp. 7277-7280, 2003.

[14] J. A. LaVerne and L. Tandon, " $\mathrm{H}_{2}$ production in the radiolysis of water on $\mathrm{UO}_{2}$ and other oxides," Journal of Physical Chemistry B, vol. 107, no. 49, pp. 13623-13628, 2003.

[15] J. A. LaVerne, " $\mathrm{H}_{2}$ formation from the radiolysis of liquid water with zirconia," Journal of Physical Chemistry B, vol. 109, no. 12, pp. 5395-5397, 2005.

[16] A. Hiroki and J. A. LaVerne, "Decomposition of hydrogen peroxide at water-ceramic oxide interfaces," Journal of Physical Chemistry B, vol. 109, no. 8, pp. 3364-3370, 2005.

[17] C. M. Lousada and M. Jonsson, "Kinetics, mechanism, and activation energy of $\mathrm{H}_{2} \mathrm{O}_{2}$ decomposition on the surface of $\mathrm{ZrO}_{2}$," Journal of Physical Chemistry C, vol. 114, no. 25, pp. 11202-11208, 2010.

[18] O. Roth, A. Hiroki, and J. A. LaVerne, "Effect of $\mathrm{Al}_{2} \mathrm{O}_{3}$ nanoparticles on radiolytic $\mathrm{H}_{2} \mathrm{O}_{2}$ production in water," Journal of Physical Chemistry C, vol. 115, no. 16, pp. 8144-8149, 2011.

[19] C. M. Lousada, A. J. Johansson, T. Brinck, and M. Jonsson, "Mechanism of $\mathrm{H}_{2} \mathrm{O}_{2}$ decomposition on transition metal oxide surfaces," Journal of Physical Chemistry C, vol. 116, no. 17, pp. 9533-9543, 2012.

[20] I. Grenthe, D. Ferri, F. Salvatore, and G. Riccio, "Studies on metal carbonate equilibria. Part 10. A solubility study of the complex formation in the uranium(VI)-water-carbon dioxide (g) system at $25^{\circ} \mathrm{C}$," Journal of the Chemical Society, Dalton Transactions, no. 11, pp. 2439-2443, 1984.

[21] D. W. Shoesmith, "Fuel corrosion processes under waste disposal conditions," Journal of Nuclear Materials, vol. 282, no. 1 , pp. 1-31, 2000.

[22] O. Roth and M. Jonsson, "Oxidation of $\mathrm{UO}_{2}(\mathrm{~s})$ in aqueous solution," Central European Journal of Chemistry, vol. 6, no. 1, pp. 1-14, 2008.

[23] T. E. Eriksen, D. W. Shoesmith, and M. Jonsson, "Radiation induced dissolution of $\mathrm{UO}_{2}$ based nuclear fuel-a critical review of predictive modelling approaches," Journal of Nuclear Materials, vol. 420, no. 1-3, pp. 409-423, 2012.

[24] F. Nielsen and M. Jonsson, "Geometrical $\alpha$ - and $\beta$-dose distributions and production rates of radiolysis products in water in contact with spent nuclear fuel," Journal of Nuclear Materials, vol. 359, no. 1-2, pp. 1-7, 2006.

[25] R. D. Astumian and Z. A. Schelly, "Geometric effects of reduction of dimensionality in interfacial reactions," Journal of the American Chemical Society, vol. 106, no. 2, pp. 304-308, 1984.

[26] M. M. Hossain, E. Ekeroth, and M. Jonsson, "Effects of $\mathrm{HCO}_{3}^{-}$on the kinetics of $\mathrm{UO}_{2}$ oxidation by $\mathrm{H}_{2} \mathrm{O}_{2}$," Journal of Nuclear Materials, vol. 358, no. 2-3, pp. 202-208, 2006.

[27] M. E. Torrero, E. Baraj, J. de Pablo, J. Giménez, and I. Casas, "Kinetics of corrosion and dissolution of uranium dioxide as a function of $\mathrm{pH}$," International Journal of Chemical Kinetics, vol. 29, no. 4, pp. 261-267, 1997.

[28] I. Casas, J. Giménez, V. Martí, M. E. Torrero, and J. de Pablo, "Kinetic-studies of unirradiated $\mathrm{UO}_{2}$ dissolution under oxidizing conditions in batch and flow experiments," Radiochimica Acta, vol. 66-67, p. 23, 1994.

[29] D. W. Shoesmith, S. Sunder, M. G. Bailey, and G. J. Wallace, "The corrosion of nuclear fuel $\left(\mathrm{UO}_{2}\right)$ in oxygenated solutions," Corrosion Science, vol. 29, no. 9, pp. 1115-1128, 1989.
[30] J. de Pablo, I. Cassas, F. Clarens, F. El Aamrani, and M. Rovira, "The effect of hydrogen peroxide concentration on the oxidative dissolution of unirradiated uranium dioxide," in 24th Scientific Basis for Nuclear Waste management, vol. 663 of MRS Proceedings, p. 409, 2001.

[31] D. W. Shoesmith and S. Sunder, "Electrochemistry-based model for the dissolution of $\mathrm{UO}_{2}$," Atomic Energy of Canada Limited, no. 10488, pp. 1-97, 1991.

[32] F. Clarens, J. de Pablo, I. Díez-Pérez, I. Casas, J. Giménez, and M. Rovira, "Formation of studtite during the oxidative dissolution of $\mathrm{UO}_{2}$ by hydrogen peroxide: a SFM study," Environmental Science and Technology, vol. 38, no. 24, pp. 6656-6661, 2004.

[33] F. Clarens, J. de Pablo, I. Casas et al., "The oxidative dissolution of unirradiated $\mathrm{UO}_{2}$ by hydrogen peroxide as a function of pH," Journal of Nuclear Materials, vol. 345, no. 2-3, pp. 225-231, 2005.

[34] J. Bruno, I. Casas, E. Cera, J. de Pablo, J. Giménez, and M. E. Torrero, "Uranium (IV) dioxide and simfuel as chemical analogues of nuclear spent fuel matrix dissolution. A comparison of dissolution results in a standard Naci/ $\mathrm{NaHCO}_{3}$ solution," in 18th Scientific Basis for Nuclear Waste Management, vol. 353 of MRS Proceedings, p. 601, 1995.

[35] J. Giménez, F. Clarens, I. Casas, M. Rovira, and J. de Pablo, "Oxidation and dissolution of $\mathrm{UO}_{2}$ in bicarbonate media: Implications for the spent nuclear fuel oxidative dissolution mechanism," Journal of Nuclear Materials, vol. 345, no. 2-3, pp. 232-238, 2005.

[36] W. J. Gray, S. A. Steward, J. C. Tait, and D. W. Shoesmith, "Interlaboratory comparison of $\mathrm{UO}_{2}$ dissolution rates," in Proceedings of the 5th Annual International High-Level Radioactive Waste Management Conference on Waste Management '94, vol. 4, p. 2597, 1994, LLNL Report UCRL-JC115356.

[37] J. de Pablo, I. Cassas, J. Giménez, M. Molera, and M. E. Torrero, "Effect of temperature and bicarbonate concentration on the kinetics of $\mathrm{UO}_{2}$ (s) dissolution under oxidizing conditions," in 20th Scienfific Basis for Nuclear Waste Management, vol. 465 of MRS Proceedings, p. 535, 1997.

[38] S. N. Nguyen, H. C. Weed, H. R. Leider, and R. B. Stout, "Dissolution kinetics of $\mathrm{UO}_{2}$. I. Flow-through tests on $\mathrm{UO}_{2.00}$ pellets and polycrystalline schoepite samples in oxygenated, carbonate/bicarbonate buffer solutions at $25^{\circ} \mathrm{C}$," in 15 th Scientific Basis for Nuclear Waste Management, vol. 257 of MRS Proceedings, p. 339, 1992.

[39] G. I. Park and H. K. Lee, "The leaching behavior of unirradiated $\mathrm{UO}_{2}$ pellets in wet storage and disposal conditions," Journal of the Korean Nuclear Society, vol. 28, p. 349, 1996.

[40] S. Sunder, D. W. Shoesmith, R. J. Lemire, M. G. Bailey, and G. J. Wallace, "The effect of ph on the corrosion of nuclear fuel $\left(\mathrm{UO}_{2}\right)$ in oxygenated solutions," Corrosion Science, vol. 32, no. 4, pp. 373-386, 1991.

[41] I. Casas, J. Giménez, V. Marti, M. E. Torrero, and J. de Pablo, "Kinetically controlled dissolution of $\mathrm{UO}_{2}(\mathrm{~s})$ under oxidizing conditions. A combined dissolution-Okidation model," in 16th Scientific Basis for Nuclear Waste Management, vol. 294 of MRS Proceedings, p. 61, 1993.

[42] M. J. Nicol, C. R. S. Needs, and N. P. Finkelstein, "Electrochemical model for the leaching of uranium dioxide: 2- alaline carbonate media," in Leaching and Reduction in Hydrometallurgy, A. R. Burkin, Ed., p. 12, IMM, London, UK, 1973. 
[43] D. E. Grandstaff, "Kinetic study of the dissolution of uraninite," Economic Geology, vol. 71, no. 8, pp. 1493-1506, 1976.

[44] S. M. Peper, L. F. Brodnax, S. E. Field, R. A. Zehnder, S. N. Valdez, and W. H. Runde, "Kinetic study of the oxidative dissolution of $\mathrm{UO}_{2}$ in aqueous carbonate media," Industrial and Engineering Chemistry Research, vol. 43, no. 26, pp. 81888193, 2004.

[45] J. B. Hiskey, "Kinetics of uranium-dioxide dissolution in ammonium carbonate," Transactions of the Institution of Mining and Metallurgy C, vol. 88, p. C145, 1979.

[46] J. de Pablo, I. Casas, J. Jiminez et al., "The oxidative dissolution mechanism of uranium dioxide. I. The effect of temperature in hydrogen carbonate medium," Geochimica et Cosmochimica Acta, vol. 63, no. 19-20, p. 3097, 1999.

[47] I. Casas, J. de Pablo, F. Clarens et al., "Combined effect of $\mathrm{H}_{2} \mathrm{O}_{2}$ and $\mathrm{HCO}_{3}^{-}$on $\mathrm{UO}_{2}(\mathrm{~s})$ dissolution rates under anoxic conditions," Radiochimica Acta, vol. 97, no. 9, pp. 485-490, 2009.

[48] E. Ekeroth, O. Roth, and M. Jonsson, "The relative impact of radiolysis products in radiation induced oxidative dissolution of $\mathrm{UO}_{2}$, " Journal of Nuclear Materials, vol. 355, no. 1-3, pp. 38-46, 2006.

[49] M. Jonsson, E. Ekeroth, and O. Roth, "Dissolution of $\mathrm{UO}_{2}$ by One- and two-electron oxidants," in 27th Scientific Basis for Nuclear Waste Management, MRS Proceedings, pp. 77-82, June 2003.

[50] C. Jégou, B. Muzeau, V. Broudic et al., "Effect of external gamma irradiation on dissolution of the spent $\mathrm{UO}_{2}$ fuel matrix," Journal of Nuclear Materials, vol. 341, no. 1, pp. 6282, 2005.

[51] W. J. Gray, "Comparison of uranium release from spent fuel and unirradiated $\mathrm{UO}_{2}$ in salt brine," in 10th Scientific Basis for Nuclear Waste management, vol. 84 of MRS Proceedings, p. 141, 1987.

[52] V. V. Rondinella, H. Matzke, J. Cobos, and T. Wiss, " $\gamma$ radiolysis and $\gamma$-radiation damage effects on $\mathrm{UO}_{2}$ dissolution under spent fuel storage conditions," in 22nd Scientific Basis for Nuclear Waste Management, vol. 556 of MRS Proceedings, p. 447, 1999.

[53] V. V. Rondinella, H. Matzke, J. Cobos, and T. Wiss, "Leaching behaviour of $\mathrm{UO}_{2}$ containing $\alpha$-emitting actinides," Radiochimica Acta, vol. 88, no. 9-11, pp. 527-532, 2000.

[54] J. Cobos, L. Havela, V. V. Rondinella et al., "Corrosion and dissolution studies of $\mathrm{UO}_{2}$ containing $\alpha$-emitters," Radiochimica Acta, vol. 90, no. 9-11, pp. 597-602, 2002.

[55] S. Stroes-Gascoyne, F. King, J. S. Betteridge, and F. Garisto, "The effects of $\alpha$-radiolysis on $\mathrm{UO}_{2}$ dissolution determined from electrochemical experiments with $238 \mathrm{Pu}$-doped $\mathrm{UO}_{2}$," Radiochimica Acta, vol. 90, no. 9-11, pp. 603-609, 2002.

[56] S. Stroes-Gascoyne, F. Garisto, and J. S. Betteridge, "The effects of $\alpha$-radiolysis on $\mathrm{UO}_{2}$ dissolution determined from batch experiments with $238 \mathrm{Pu}$-doped $\mathrm{UO}_{2}$," Journal of Nuclear Materials, vol. 346, no. 1, pp. 5-15, 2005.

[57] T. Mennecart, B. Grambow, M. Fattahi, and Z. Andriambololona, "Effect of $\alpha$ radiolysis on doped $\mathrm{UO}_{2}$ dissolution under reducing conditions," Radiochimica Acta, vol. 92, no. 9-11, pp. 611-615, 2004.

[58] D. W. Shoesmith and F. King, "A mixed potential model for the prediction of the effects of $\alpha$ radiolysis, precipitation and redox processes on the dissolution of used nuclear fuel," Ontario Power Generation Report No. 06819-REP-012000038 R00, 1998.

[59] M. Trummer, S. Nilsson, and M. Jonsson, "On the effects of fission product noble metal inclusions on the kinetics of radiation induced dissolution of spent nuclear fuel," Journal of Nuclear Materials, vol. 378, no. 1, pp. 55-59, 2008.

[60] M. Trummer, O. Roth, and M. Jonsson, " $\mathrm{H}_{2}$ inhibition of radiation induced dissolution of spent nuclear fuel," Journal of Nuclear Materials, vol. 383, no. 3, pp. 226-230, 2009.

[61] M. Trummer, B. Dahlgren, and M. Jonsson, "The effect of $\mathrm{Y}_{2} \mathrm{O}_{3}$ on the dynamics of oxidative dissolution of $\mathrm{UO}_{2}$," Journal of Nuclear Materials, vol. 407, no. 3, pp. 195-199, 2010.

[62] C. M. Lousada, M. Trummer, and M. Jonsson, "Reactivity of $\mathrm{H}_{2} \mathrm{O}_{2}$ towards different $\mathrm{UO}_{2}$ based materials. The relative impact of radiolysis products," Journal of Nuclear Materials. In press.

[63] R. Pehrman, M. Trummer, C. M. Lousada, and M. Jonsson, "On the redox reactivity of doped $\mathrm{UO}_{2}$ pellets-influence of dopants on the $\mathrm{H}_{2} \mathrm{O}_{2}$ decomposition mechanism," Journal of Nuclear Materials, vol. 430, no. 1-3, pp. 6-11, 2012.

[64] S. Nilsson and M. Jonsson, " $\mathrm{H}_{2} \mathrm{O}_{2}$ and radiation induced dissolution of $\mathrm{UO}_{2}$ and SIMFUEL pellets," Journal of Nuclear Materials, vol. 410, no. 1-3, pp. 89-93, 2011.

[65] M. Jonsson, F. Nielsen, O. Roth, E. Ekeroth, and M. M. Hossain, "Radiation induced spent nuclear fuel dissolution under deep repository conditions," Environmental Science and Technology, vol. 41, no. 20, pp. 7087-7093, 2007.

[66] O. Roth, M. Trummer, and M. Jonsson, "Factors influencing the rate of radiation-induced dissolution of spent nuclear fuel," Research on Chemical Intermediates, vol. 35, no. 4, pp. 465-478, 2009.

[67] M. Yang, A. Barreiro Fidalgo, S. Sundin, and M. Jonsson, "Inhibition of radiation induced dissolution of $\mathrm{UO}_{2}$ by sulfide- a comparison with the hydrogen effect," Journal of Nuclear Materials. In press.

[68] M. Trummer and M. Jonsson, "Resolving the $\mathrm{H}_{2}$ effect on radiation induced dissolution of $\mathrm{UO}_{2}$-based spent nuclear fuel," Journal of Nuclear Materials, vol. 396, no. 2-3, pp. 163169, 2010.

[69] E. Ekeroth, M. Jonsson, T. E. Eriksen, K. Ljungqvist, S. Kovács, and I. Puigdomenech, "Reduction of $\mathrm{UO}_{2}^{2+}$ by $\mathrm{H}_{2}$," Journal of Nuclear Materials, vol. 334, no. 1, pp. 35-39, 2004.

[70] S. Nilsson and M. Jonsson, "On the catalytic effect of $\mathrm{Pd}(\mathrm{s})$ on the reduction of $\mathrm{UO}_{2}^{2+}$ with $\mathrm{H}_{2}$ in aqueous solution," Journal of Nuclear Materials, vol. 374, no. 1-2, pp. 290-292, 2008.

[71] M. E. Broczkowski, J. J. Noel, and D. W. Shoesmith, "The inhibiting effects of hydrogen on the corrosion of uranium dioxide under nuclear waste disposal conditions," Journal of Nuclear Materials, vol. 346, no. 1, pp. 16-23, 2005.

[72] T. E. Eriksen, M. Jonsson, and J. Merino, "Modelling of time resolved and long contact time dissolution studies of spent nuclear fuel in $10 \mathrm{mM}$ carbonate solution-a comparison between two different models and experimental data," Journal of Nuclear Materials, vol. 375, no. 3, pp. 331-339, 2008.

[73] F. Nielsen, K. Lundahl, and M. Jonsson, "Simulations of $\mathrm{H}_{2} \mathrm{O}_{2}$ concentration profiles in the water surrounding spent nuclear fuel," Journal of Nuclear Materials, vol. 372, no. 1, pp. 32-35, 2008.

[74] F. Nielsen and M. Jonsson, "Simulations of $\mathrm{H}_{2} \mathrm{O}_{2}$ concentration profiles in the water surrounding spent nuclear fuel taking mixed radiation fields and bulk reactions into account," Journal of Nuclear Materials, vol. 374, no. 1-2, pp. 281-285, 2008.

[75] F. Nielsen, E. Ekeroth, T. E. Eriksen, and M. Jonsson, "Simulation of radiation induced dissolution of spent nuclear fuel using the steady-state approach. A comparison to 
experimental data," Journal of Nuclear Materials, vol. 374, no. 1-2, pp. 286-289, 2008.

[76] G. Hultquist, "Hydrogen evolution in corrosion of copper in pure water," Corrosion Science, vol. 26, no. 2, pp. 173-177, 1986.

[77] P. Szakálos, G. Hultquist, and G. Wikmark, "Corrosion of copper by water," Electrochemical and Solid-State Letters, vol. 10, no. 11, pp. C63-C67, 2007.

[78] P. Szakalos, G. Hulquist, and G. Wikmark, "Response to the comment on "corrosion of copper by water" [Electrochem. Solid-State Lett. , 10 , C63 , (2007)]," Electrochemical and Solid-State Letters, vol. 11, no. 4, p. S2, 2008.

[79] G. Hultquist, M. J. Graham, P. Szakalos, G. I. Sproule, A. Rosengren, and L. Grasjo, "Hydrogen gas production during corrosion of copper by water," Corrosion Science, vol. 53, no. 1, pp. 310-319, 2011.

[80] J. P. Simpson, "The influence of radiation on the corrosion of copper," Nagra Technical Report 84-01, 1984.

[81] C. Corbel, D. Feron, M. Roy, F. Maurel, V. Wasselin-Trupin, and B. Hickel, "Effect of irradiation on long term alteration of oxides and metals in aqueous solutions," in Prediction of Long Term Corrosion Behaviour in Nuclear Waste Systems, D. D. Macdonald and D. Féron, Eds., p. 500, Maney Publishing, London, UK, 2003.

[82] W. H. Yunker and R. S. Glass, "Long-term corrosion behavior of copper-base materials in a $\gamma$-irradiated environment," in 10th Scientific Basis for Nuclear Waste Management, vol. 84 of MRS Proceedings, p. 579, 1986.

[83] D. T. Reed and R. A. van Konynenburg, "Corrosion of copper-based materials in irradiated moist air systems," in 14th Scientific Basis for Nuclear Waste Management, vol. 212, p. 317, 1990.

[84] D. T. Reed, V. Swayambunathan, B. S. Tani, and R. A. van Konynenburg, "Corrosion product identification and relative rates of corrosion of candidate metals in an irradiated airsteam environment," in 13th Scientific Basis for Nuclear Waste Management, vol. 176 of MRS Proceedings, p. 517, 1989.

[85] N. G. Petrik, M. N. Petrov, and V. G. Fomin, "Radiolysis and corrosion in copper-water-free volume system," High Energy Chemistry, vol. 31, no. 5, pp. 308-311, 1997.

[86] C. D. Litke and F. King, "The corrosion of copper in synthetic groundwater at $150^{\circ} \mathrm{C}$ part 1 . The results of short-term electrochemical tests," Atomic Energy of Canada Limited Technical Record TR-428, 14, Atomic Energy of Canada Limited, 1987.

[87] Å. Björkbacka, S. Hosseinpour, C. Leygraf, and M. Jonsson, "Radiation induced corrosion of copper in anoxic aqueous solution," Electrochemical and Solid-State Letters, vol. 15, no. 5, pp. C5-C7, 2012.

[88] Å. Björkbacka, S. Hosseinpour, M. Johnson, C. Leygraf, and M. Jonsson, Environmental Science and Technology. In press.

[89] F. Bergaya, B. K. G. Theng, and G. Lagaly, Handbook of Clay Science, Elsevier Science, Amsterdam, The Netherlands, 2006.

[90] D. Gournis, A. E. Mantaka-Marketou, M. A. Karakassides, and D. Petridis, "Effect of $\gamma$-irradiation on clays and organoclays: a Mossbauer and XRD study," Physics and Chemistry of Minerals, vol. 27, no. 7, pp. 514-521, 2000.

[91] A. Negron, S. Ramos, A. L. Blumenfeld, G. Pacheco, and J. J. Fripiat, "On the structural stability of montmorillonite submitted to heavy $\gamma$-irradiation," Clays and Clay Minerals, vol. 50, no. 1, pp. 35-37, 2002.

[92] R. Pushkareva, E. Kalinichenko, A. Lytovchenko, A. Pushkarev, V. Kadochnikov, and M. Plastynina, "Irradiation effect on physico-chemical properties of clay minerals," Applied Clay Science, vol. 21, no. 1-2, pp. 117-123, 2002.

[93] M. Plötze, G. Kahr, and R. H. Stengele, "Alteration of clay minerals-gamma-irradiation effects on physicochemical properties," Applied Clay Science, vol. 23, no. 1-4, pp. 195202, 2003.

[94] W. H. Huang and W. C. Chen, "Swelling behavior of a potential buffer material under simulated near field environment," Journal of Nuclear Science and Technology, vol. 41, no. 12, pp. 1271-1279, 2004.

[95] M. Holmboe, M. Jonsson, and S. Wold, "Influence of $\gamma$-radiation on the reactivity of montmorillonite towards $\mathrm{H}_{2} \mathrm{O}_{2}$," Radiation Physics and Chemistry, vol. 81, no. 2, pp. 190-194, 2012.

[96] M. Holmboe, K. K. Norrfors, M. Jonsson, and S. Wold, "Effect of $\gamma$-radiation on radionuclide retention in compacted bentonite," Radiation Physics and Chemistry, vol. 80, no. 12, pp. 1371-1377, 2011.

[97] S. Garcia-Garcia, M. Jonsson, and S. Wold, "Temperature effect on the stability of bentonite colloids in water," Journal of Colloid and Interface Science, vol. 298, no. 2, pp. 694-705, 2006.

[98] S. Garcia-Garcia, S. Wold, and M. Jonsson, "Kinetic determination of critical coagulation concentrations for sodiumand calcium-montmorillonite colloids in $\mathrm{NaCl}$ and $\mathrm{CaCl}_{2}$ aqueous solutions," Journal of Colloid and Interface Science, vol. 315, no. 2, pp. 512-519, 2007.

[99] S. García-García, S. Wold, and M. Jonsson, "Effects of temperature on the stability of colloidal montmorillonite particles at different $\mathrm{pH}$ and ionic strength," Applied Clay Science, vol. 43, no. 1, pp. 21-26, 2009.

[100] S. Garcia-Garcia, C. Degueldre, S. Wold, and S. Frick, "Determining pseudo-equilibrium of montmorillonite colloids in generation and sedimentation experiments as a function of ionic strength, cationic form, and elevation," Journal of Colloid and Interface Science, vol. 335, no. 1, pp. 54-61, 2009.

[101] M. Holmboe, S. Wold, M. Jonsson, and S. Garcia-Garcia, "Effects of $\gamma$-irradiation on the stability of colloidal $\mathrm{Na}^{+}$Montmorillonite dispersions," Applied Clay Science, vol. 43, no. 1, pp. 86-90, 2009. 

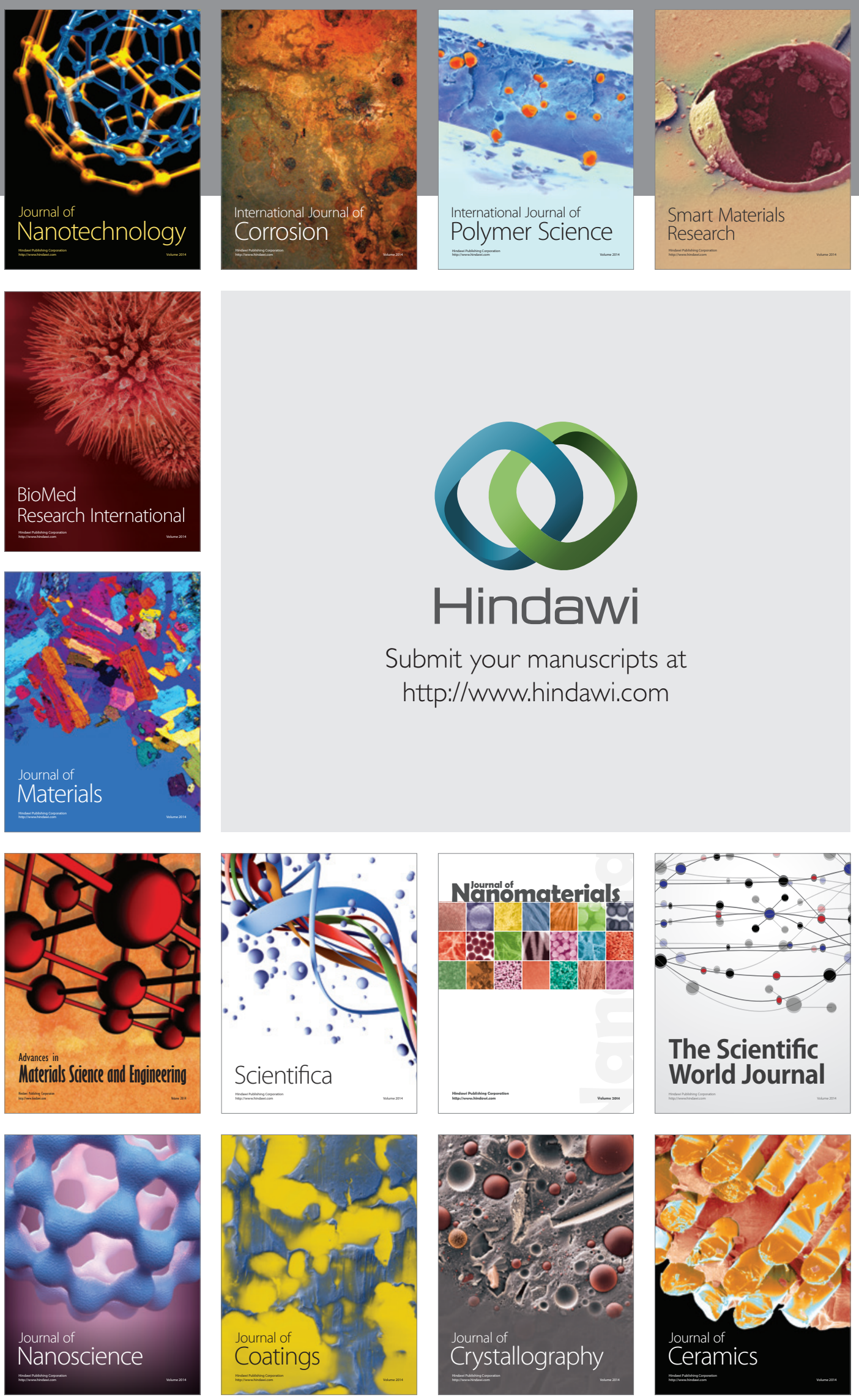

The Scientific World Journal

Submit your manuscripts at

http://www.hindawi.com

\section{World Journal}

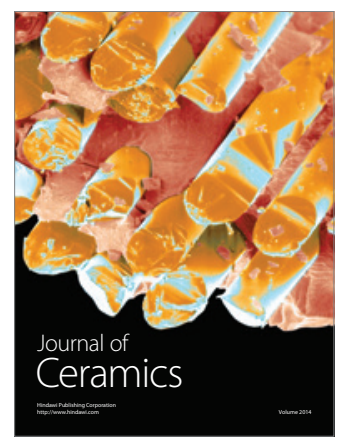

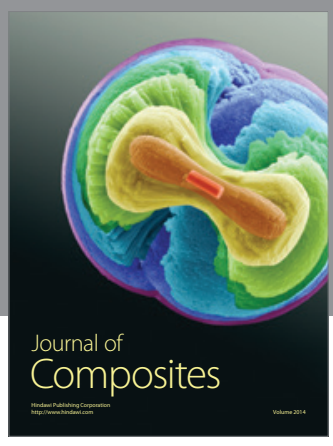
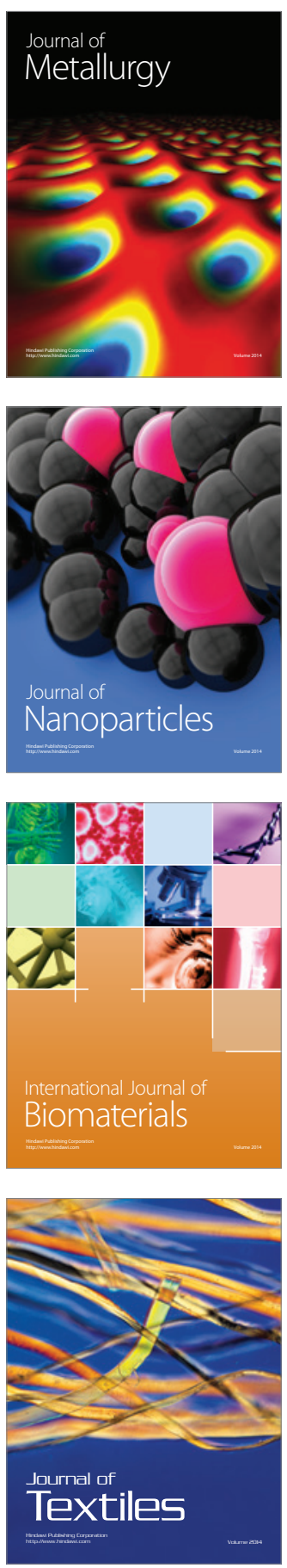